03

\title{
Генерация поверхностного потока жидкости в каналах капиллярными колебаниями и волнами
}

\author{
(C) В.А. Александров \\ Институт механики УдмФИЦ УрО РАН, \\ 426067 Ижевск, Россия \\ e-mail: ava@udman.ru
}

Поступило в Редакцию 25 мая 2021 г.

В окончательной редакции 15 ноября 2021 r.

Принято к публикации 16 ноября 2021 г.

Обнаружена и исследована генерация направленного потока жидкости на поверхности воды в каналах с источниками и резонаторами капиллярных колебаний. Поверхностный поток обусловлен движением жидкости через щели между резонаторами, а также между резонатором и стенками канала под искривленную поверхность, локально деформируемую источниками капиллярных колебаний, переносом энергии локально искривленной поверхности жидкости капиллярными волнами и передачей импульса волн частицам поверхности жидкости в одном направлении. Показано, что капиллярные волны вместе с энергией переносят избыточную поверхность, плотность потока которой равна потоку деформации поверхности. Проемонстрированы движущиеся устройства с капиллярно-волновым ускорителем поверхностного потока жидкости.

Ключевые слова: капиллярные колебания и волны, поверхностный поток жидкости, канал, поток деформации поверхности.

DOI: $10.21883 /$ JTF.2022.02.52008.158-21

\section{Введение}

Капиллярные волны на поверхности жидкости возбуждаются за счет инерционных колебаний жидкости вместе с емкостью, а также колебаний различных тел на поверхности жидкости. Простым способом возбуждения капиллярных волн является использование стержней и пластин, вибрации которых возбуждаются пьезоэлектрическим преобразователем и передаются жидкости. Вибрирующие стержни и пластины в контакте со свободной поверхностью жидкости возбуждают капиллярные волны с распределенной амплитудой, создающие, в свою очередь, на поверхности жидкости струйные и вихревые течения. Генерация одновременно нескольких вихревых течений на поверхности жидкости наблюдается в случае взаимодействия с жидкостью горизонтально расположенной вибрирующей пластины со свободными краями, так как в такой пластине пучности изгибных колебаний расположены по ее краям и эти пучности являются источниками капиллярных колебаний и волн на свободной поверхности жидкости [1]. Картина вихревых течений на поверхности жидкости, исходящих от каждой пучности колебаний краев пластины, может быть одинаковой, несмотря на то, что колебания в соседних пучностях на краях пластины происходят в противофазе. Возбуждение двумерных капиллярных волн на поверхности жидкости вибрирующими упругими телами, в частности в виде ряби Фарадея, и образование поверхностных потоков являются пороговыми, что характерно для параметрического возбуждения нелинейных капиллярных волн конечной амплитуды [2]. При достаточно больших амплитудах колебаний источника капиллярные колебания и волны могут проявлять нелинейность, связанную с локальной деформацией свободной поверхности жидкости вблизи источника, при этом возможны проявление эффективного вибрационного поверхностного натяжения жидкости и вибрационная конвекция Марангони [3].

Локальная деформация свободной поверхности жидкости возможна также при кратковременном взаимодействии с отдельными частицами в виде падающих капель жидкости различной природы. В результате исследований быстропротекающих процессов погружения свободно упавшей капли воды в покоящуюся воду методом высокоразрешающей фото- и видеорегистрации [4] получены изображения капиллярных волн и микротечений как на поверхности капли, погружающейся в жидкость, так и на поверхности принимающей жидкости. Исследования всплеска капли [5] также показали генерацию капиллярных волн на поверхности погружающихся капель жидкости и возникновение течений, в которых вещество капли собирается в тонкие линейчатые структуры - лигаменты. Образование лигаментов оказывается возможным и в двуслойном потоке вязких жидкостей, движущихся относительно друг от друга. На межфазной границе жидкостей, движущихся в микроканале с различным объемным потоком, обнаруживаются вязкие волны и увлекаемые ими лигаменты в виде прослоек жидкости [6]. Еще одним способом локального возбуждения капиллярных волн и течений на свободной поверхности жидкости является воздействие на поверхность жидкости импульсами лазера. В [7] проведен ряд экспериментов по лазерному возбуждению 
конвекции Марангони и капиллярных волн на поверхности феррожидкости при воздействии сфокусированным лазерным излучением мощностью $1 \mathrm{~W}$. Показано, что тепловое воздействие непрерывного излучения приводит к конвекции с образованием выступов на поверхности даже глубокой жидкости, а воздействие модулированного излучения - к генерации капиллярных волн. Использование лазера дает возможность получения термокапиллярной конвекции Марангони и в отдельных каплях жидкости, как это было сделано в [8] при облучении капли, вихревые течения в которой визуализировались потоками углеродных нанотрубок. Исследованиями динамики слоя вязкой жидкости в виде силиконового масла на поверхности вибрирующей пластины со свободными краями, возбужденной пьезопреобразователем, нами были получены явления перемещения слоя жидкости по поверхности вибрирующей пластины к участкам ее поверхности с образованием отдельных капель [9]. Ярко выраженные генерация капиллярных волн и вибрационная конвекция с образованием вихревых течений, переходящих в возвратную струйку, проявляются в каплях масла, находящихся на участках края пластины с пучностями изгибных колебаний. В целом капиллярные волны, возбуждаемые как инерционными вибрациями жидкости, так и локализованными источниками на поверхности жидкости, осуществляют перенос частиц жидкости, создавая поверхностные вихревые и струйные течения. Исследование механизмов образования генерации поверхностных потоков в жидкости капиллярными волнами представляет интерес для создания устройств и технологий получения управляемых направленных потоков.

Целью настоящей работы являлось исследование потоков на поверхности воды, создаваемых капиллярными колебаниями и волнами, возбуждаемыми локально распределенными источниками при их синфазных колебаниях и направленных потоков в каналах с источниками и резонаторами капиллярных колебаний.

\section{1. Постановка экспериментов}

Устройство для возбуждения синфазных капиллярных колебаний содержит пьезоэлектрический преобразователь с плоским круглым корпусом FML-27T-3.9A1-100 в качестве источника колебаний и присоединенный к нему упругий волновод в виде двух одинаковых металлических стержней диаметром $0.6 \mathrm{~mm}$ и длиной $40 \mathrm{~mm}$ со свободными концами, разнесенными на расстоянии $12 \mathrm{~mm}$ друг от друга. В качестве упругого волновода использовались также прямоугольные пластины из стали толщиной $0.1 \mathrm{~mm}$ и из полиэтилентерефталата (РЕТ) толщиной $0.3 \mathrm{~mm}$. В случае пластинчатых волноводов на их свободном торцевом краю были выполнены осцилляторы путем удаления части пластины, или к свободному торцевому краю пластины приклеивались короткие проволочные стержни. Устройство закреплено на штативе струбцинами через держатель, припаянный к краю корпуса пьезоэлектрического преобразователя на диаметрально противоположном волноводу участке. Свободные концы стержней подводятся к поверхности воды, налитой в прозрачную стеклянную чашку Петри диаметром $100 \mathrm{~mm}$, расположенную на столике с подъемным механизмом. Поверхность воды освещается полупроводниковым светодиодным импульсным источником света, частота импульсов света регулируется электронным ключом, управляемым генератором прямоугольных сигналов. При подаче переменного напряжения от усилителя сигналов генератора низкой частоты на электроды пьезоэлектрического преобразователя в его корпусе возбуждаются изгибные колебания, которые, в свою очередь, передаются стержням и приводят концы стержней в колебательное движение. Смоченные поверхности концов стержней при колебаниях на поверхности воды синфазно возбуждают капиллярные колебания, распространяющиеся по поверхности воды в виде капиллярных волн. Интерференционная картина волн наблюдается при стробоскопическом освещении поверхности жидкости, поверхностные течения, создаваемые волнами, визуализируются частицами графита или люминофора. Капиллярные волны и течения на поверхности воды фиксировались цифровым фотоаппаратом.

\section{2. Результаты и их обсуждение}

\section{1. Поверхностные потоки от двух источников капиллярных колебаний}

Капиллярные колебания на свободной поверхности воды, возбуждаемые двумя синфазно вибрирующими источниками, распространяются в виде цилиндрических капиллярных волн, бегущих от участков контакта стержней с поверхностью воды (рис. 1). Волны на поверхности воды интерферируют, и при определенных частотах вибрации стержней на участке поверхности воды между концами стержней возбуждаются капиллярные колебания в виде стоячей волны, линии гребней которой оказываются поперечными отрезку между концами стержней. Стоячая капиллярная волна образуется при возбуждении волн частотой, при которой на отрезке линии поверхности воды между источниками укладывается целое число половин длины волны. Одновременно с этим на поверхности воды генерируются две пары вихревых течений, визуализируемых трассерными частицами, движение которых происходит по замкнутым вытянутым траекториям (рис. 1,a). В каждой паре течений, отстоящих по обе стороны от каждого источника колебаний, общее течение направлено в сторону от источников по линии, пересекающей источники. Обратное движение частиц в вихревых течениях направлено к участку поверхности жидкости между двумя источниками волн перпендикулярно к отрезку линии между ними. С увеличением частоты колебаний стержней длина капиллярных волн уменьшается, при определенных частотах колебаний 

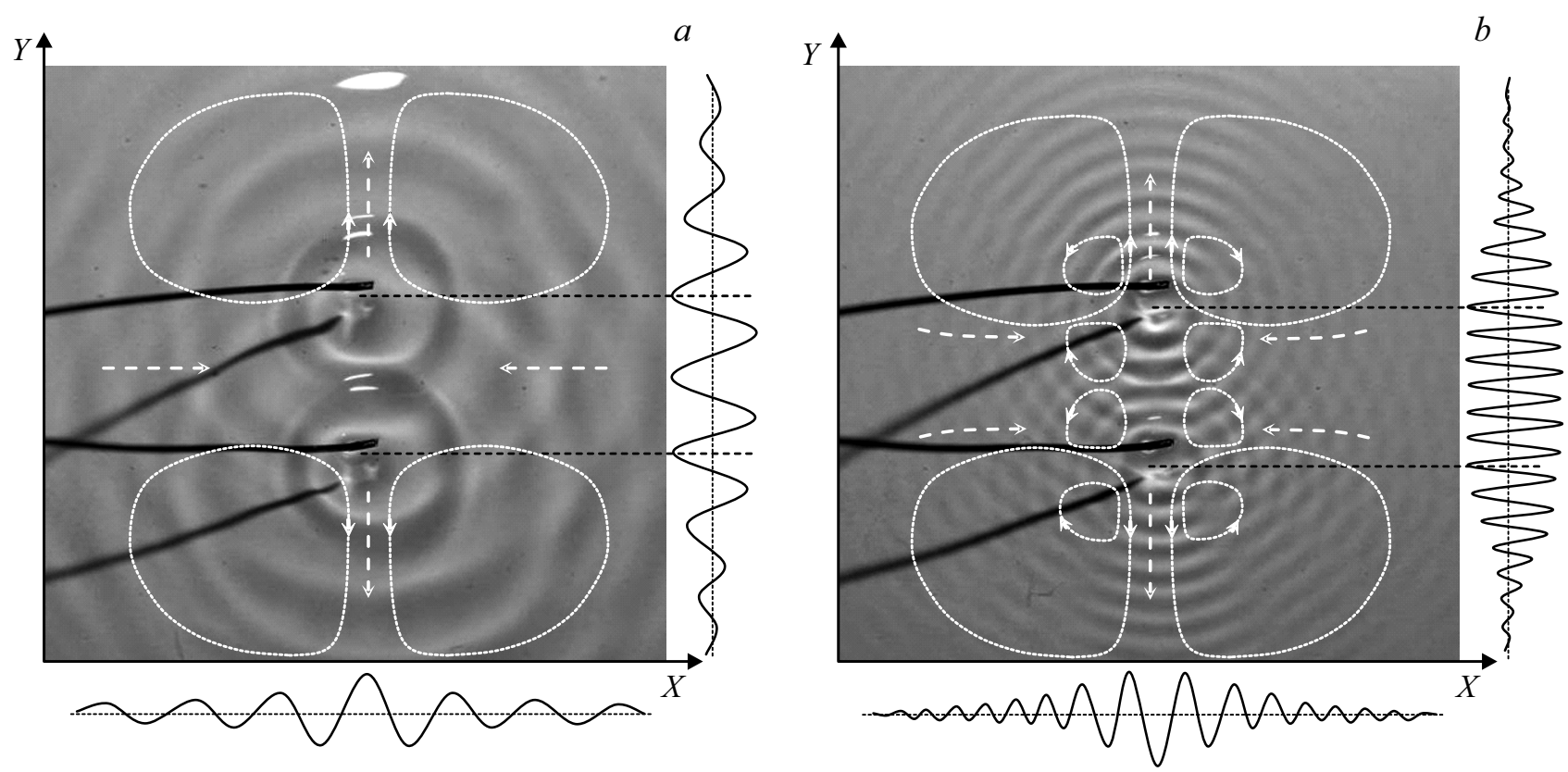

Рис. 1. Интерференционная картина капиллярных волн, схема траекторий движения частиц на поверхности воды и профили волн, возбуждаемых двумя источниками, синфазно вибрирующими с частотой $46(a)$ и $200 \mathrm{~Hz}(b)$.

стержней на участке поверхности воды между концами стержней вновь образуются стоячие волны. При этом скорости движения трассерных частиц в вихревых течениях увеличиваются, и наблюдается образование вторичных мелкомасштабных вихрей (рис. 1,b). В целом картина вихревых плоских течений на поверхности воды, создаваемых двумя синфазно вибрирующими источниками капиллярных волн (рис. 2,a), является аналогичной картине течений на поверхности воды вблизи краев вибрирующей в ней пластины, на поверхности слоя жидкости и отдельной капли на вибрирующей пластине и мыльной пленке воды на отверстиях в пластине.

\section{2. Деформация свободной поверхности жидкости капиллярными колебаниями и поток деформации в цилиндрической капиллярной волне}

Генерацию вихревых течений на поверхности жидкости двумя разнесенными источниками капиллярных волн можно объяснить следующим образом.

Свободные концы стержней за счет явления смачивания осуществляют капиллярный подъем жидкости, в результате которого площадь контакта жидкости с поверхностью стержней увеличивается, а свободная поверхность воды искривляется. При вибрациях стержней угол смачивания периодически изменяется, что приводит к локальному изменению искривленной свободной поверхности жидкости вблизи межфазной границы. Если выделить элемент поверхности жидкости $\Delta S_{0}$ в неподвижной относительно вибрирующей поверхности системе координат, то его энергия в условиях капиллярных колебаний составит

$$
\Delta W_{s}=\sigma\left(\Delta S_{0}+\Delta S_{v}\right)
$$

где $\Delta S_{v}$ - приращение площади элемента поверхности жидкости в колебательном процессе. Эту энергию можно описать через относительную деформацию (в дальнейшем просто деформацию) элемента поверхности жидкости $\delta=\Delta S_{v} / \Delta S_{0}$ уравнением

$$
\Delta W_{s}=\sigma(1+\delta) \Delta S_{0} .
$$

Таким образом, энергия элемента свободной поверхности жидкости при капиллярных колебаниях изменяется вследствие деформации поверхности колебаниями. Плотность избыточной энергии элемента поверхности жидкости при этом равна произведению поверхностного натяжения и деформации $\sigma_{v}=\sigma \delta$. Энергия элемента свободной поверхности жидкости и его площадь при капиллярных колебаниях вблизи источника изменяются с удвоенной частотой колебаний по пульсирующему закону, поэтому можно считать, что вибрирующая поверхность приобретает избыточную осредненную энергию за период колебаний по сравнению с неподвижным участком поверхности. Плотность избыточной поверхностной энергии в среднем при этом равна $\Delta \bar{w}_{s}=\bar{\sigma}_{v}=\bar{\delta} \sigma$. Эта избыточная плотность поверхностной энергии имеет физический смысл эффективного вибрационного поверхностного натяжения, которое в экспериментах приводит к вибрационной конвекции Марангони. Вибрационная конвекция на поверхности воды в виде течений, переходящих в струи, наблюдается, например, при параметрическом возбуждении капиллярных колебаний 
$a$


Рис. 2. Картина распределения частиц люминофора в вихревых течениях, создаваемых на поверхности воды волнами от двух источников, синфазно вибрирующих частотой $46 \mathrm{~Hz}$ (стрелками указаны направления движения течений) (a) и схема интерференции волн $(b)$.

вибрирующей пластиной [1]. Вибрационную конвекцию обычно объясняют возникновением градиента эффективного поверхностного натяжения. В рассматриваемом случае эффективное поверхностное натяжение прямо пропорционально деформации поверхности жидкости и вибрационную конвекцию можно объяснить градиентом деформации поверхности.

Для того чтобы установить зависимость деформации поверхности жидкости от плотности энергии, передаваемой вибрирующим источником этой поверхности, рассмотрим процесс возбуждения капиллярных колебаний и волн на свободной поверхности жидкости одним источником - стержнем, конец которого подведен к поверхности жидкости. Движение стержня при вибрациях передается жидкости и ее частицы непосредственно вблизи поверхности стержня приобретают кинетическую энергию, плотность $w_{k}$ которой пропорциональна квадрату колебательной скорости $v$ поверхности стержня: $w_{k}=(1 / 2) \rho_{l} v^{2}$, где $\rho_{l}-$ плотность жидкости. В условиях радиальной симметрии межфазной границы контакта жидкости и стрежня его вибрации приводят к возбуждению капиллярных колебаний на свободной поверхности жидкости, которые распространяются вдоль поверхности жидкости в виде цилиндрических капиллярных волн. Участок искривленной поверхности жидкости с максимальной амплитудой колебаний отстоит от центра контакта с поверхностью вибрирующего стержня на некотором расстоянии $r_{0}$, при этом смещения частиц поверхности жидкости происходят как в поперечном, так и в продольном направлении к этой поверхности. В таком случае уравнения для поперечных и продольных смещений $\eta$ и $\xi$ в цилиндрической капиллярной волне можно записать в виде

$$
\eta=\eta_{0} \sqrt{r_{0} / r} \cos (\omega t-k r)
$$

и

$$
\zeta=\xi_{0} \sqrt{r_{0} / r} \sin (\omega t-k r)
$$

где $\eta_{0}$ и $\xi_{0}$ - амплитуды смещений частиц жидкости в колебаниях вблизи межфазной границы с поверхностью вибрирующего стержня, $\omega$ - частота волн, $k=\omega / c_{c}=2 \pi / \lambda_{c}-$ волновое число, в котором $c_{c}$ и $\lambda_{c}-$ соответственно фазовая скорость и длина капиллярной волны, $r \geq r_{0}-$ расстояние. Частицы поверхности жидкости при колебаниях в цилиндрической волне движутся по эллиптическим траекториям, описываемым уравнением

$$
\eta^{2} / \eta_{0}^{2}+\xi^{2} / \xi_{0}^{2}=r_{0} / r
$$

Плотность кинетической энергии частиц поверхности жидкости определяется через их скорости в колебательном движении $w_{k}=(1 / 2) \rho_{l}\left[(d \eta / d t)^{2}+(d \xi / d t)^{2}\right]$. Подстановка в это уравнение производных с учетом тригонометрических соотношений $\sin ^{2} x=(1 / 2)(1-\cos 2 x)$ и $\cos ^{2} x=(1 / 2)(1+\cos 2 x)$ дает следующее выражение для плотности кинетической энергии:

$$
\begin{aligned}
w_{k}= & (1 / 4) \rho_{l} \omega^{2}\left(\eta_{0}^{2}+\xi_{0}^{2}\right)\left(r_{0} / r\right) \\
& +(1 / 4) \rho_{l} \omega^{2}\left(\xi_{0}^{2}-\eta_{0}^{2}\right)\left(r_{0} / r\right) \cos 2(\omega t-k x)
\end{aligned}
$$

Согласно этому уравнению, плотность кинетической энергии частиц поверхности жидкости в капиллярной волне изменяется с удвоенной частотой волн, а ее величина в среднем за период колебаний равна $\bar{w}_{k}=(1 / 4) \rho_{l} v_{0}^{2}\left(r_{0} / r\right)$, где $v_{0}=\omega \sqrt{\eta_{0}^{2}+\zeta_{0}^{2}}-$ скорость 
смещения частиц поверхности жидкости вблизи источника на расстоянии $r=r_{0}$.

В реальных жидкостях из-за вязкости колебания и волны затухают. В работе [10] проведен анализ дисперсии и затухания капиллярных волн конечной амплитуды, где указывается, что частота капиллярных волн в вязкой жидкости определяется выражением $\omega=\omega_{0}+i \gamma=\omega_{0} \sqrt{1-\xi^{2}}$. Режимы затухания зависят от вязкого коэффициента частоты $\xi=\gamma / \omega_{0}$. В случае возбуждения волн на свободной поверхности однородной жидкости коэффициент затухания волн определяется как $\gamma=2 v k^{2}$, что подходит к настоящей работе для волн, возбуждаемых на поверхности воды.

Дисперсионное уравнение для капиллярных волн на свободной поверхности вязкой жидкости, глубина $H$ которой составляет половину длины волны и более, $H \geq \lambda_{c} / 2$, в соответствии с частотным уравнением можно записать в виде

$$
\omega^{2}=\omega_{0}^{2}-4 v^{2} k^{4}
$$

где $\omega_{0}^{2}=\left(\sigma / \rho_{l}\right) k_{0}^{3}=\kappa_{0}^{2} c_{c 0}^{2}$.

Из дисперсионного уравнения можно получить выражение для скорости капиллярных волн в виде

$$
c_{c}=\left(\omega_{0} / k\right) \sqrt{1-4 v^{2} k^{4} / \omega_{0}^{2}} .
$$

Это выражение может быть записано через частоту $f$ и длину $\lambda_{c}$ возбуждаемых волн, которые могут быть определены из эксперимента:

$$
c_{c}=f \lambda_{c} \sqrt{1-16 \pi^{2} v^{2} / f^{2} \lambda_{c}^{4}}
$$

Согласно этому выражению, вязкие потери скорости капиллярных волн должны увеличиваться с увеличением частоты и уменьшением длины волн. Расчеты, сделанные исходя из физических характеристик воды, для которой плотность $\rho_{l}$ составляет $10^{3} \mathrm{~kg} / \mathrm{m}^{3}$, поверхностное натяжение $\sigma-72.8 \cdot 10^{-3} \mathrm{~N} / \mathrm{m}$ и кинематическая вязкость $v-1.006 \cdot 10^{-6} \mathrm{~m}^{2} / \mathrm{s}$, позволяют сделать вывод о том, что при низких частотах волн вязкие потери скорости волн являются несущественными. Так, исходя из картины волн, возбуждаемых на поверхности воды двумя синхронно вибрирующими источниками, длина $\lambda_{c}$ капиллярной волны при частотах колебаний источников 46 и $200 \mathrm{~Hz}$ составляет соответственно 6 и $2 \mathrm{~mm}$. Скорости волн при этих частотах, определяемые из эксперимента по формуле $c_{c}=f \lambda_{c}$, равны $c_{c}=276.0 \cdot 10^{-3}$ и $400.0 \cdot 10^{-3} \mathrm{~m} / \mathrm{s}$. Второе слагаемое $16 \pi^{2} v^{2} / f^{2} \lambda_{c}^{4}$ в подкоренном множителе в выражении для скорости волн частотой $46 \mathrm{~Hz}$ составляет $58 \cdot 10^{-6}$, частотой $200 \mathrm{~Hz}-$ $25 \cdot 10^{-5}$, что намного меньше единицы. Однако экспериментально определяемые значения скорости капиллярных волн все же немного меньше их значений, вычисленных по формуле $c_{c}(f)=\sqrt[3]{2 \pi f \sigma / \rho_{l}}$, в которой не учитывается вязкость воды. Расчеты дают следующие значения скорости волн на поверхности воды: $c_{c}(46)=276.1 \cdot 10^{-3}$ и $c_{c}(200)=450.6 \cdot 10^{-3} \mathrm{~m} / \mathrm{s}$. Для высоких частот длина волны уменьшается, а волновое число увеличивается, поэтому вязкие потери скорости волн возрастают.

В экспериментах с генерацией поверхностных потоков капиллярными колебаниями на поверхности воды наблюдаются возбуждения монохроматических волн, в которых фазовая и групповая скорости равны друг другу. Заметим, что для жидкости с нулевой вязкостью фазовая скорость капиллярной волны равна $c_{c}=\sqrt{\left(\sigma / \rho_{l}\right) k}$, групповая скорость $d \omega / d k=(3 / 2) c_{c}$. В целом вязкость жидкости приводит к снижению фазовой и групповой скоростей капиллярных волн на ее свободной поверхности.

Энергия волн в вязкой жидкости уменьшается по экспоненциальному закону $\mathbf{E} \propto \exp (-2 \gamma t)$ [11]. Так как капиллярные колебания, возбуждаемые источниками, являются вынужденными и распространяются вдоль поверхности жидкости в виде бегущих волн, энергия волн на определенном расстоянии от источника уменьшится в $\exp \left(-4 v k^{2} \Delta x / c_{c}\right)$ раз. Степень экспоненты можно привести к выражению $\left(-16 \pi^{2} v \Delta x / f \lambda_{c}^{3}\right)$. Отсюда можно оценить, на каком расстоянии от источника энергия волн уменьшится в $e$ раз. Опять же, исходя из экспериментов для частоты волн $46 \mathrm{~Hz}$, это расстояние составляет около $62 \mathrm{~mm}$ или $\Delta x \approx 10 \lambda_{c}$, для частоты $200 \mathrm{~Hz}-\Delta x \approx 10 \mathrm{~mm}$ или $\Delta x \approx 5 \lambda_{c}$. Таким образом, небольшая вязкость воды позволяет наблюдать волновое поле практически на всей поверхности воды в чашке Петри диаметром $100 \mathrm{~mm}$. Для сравнения на поверхности силикатного масла ПМС-100, кинематическая вязкость которой составляет $v=100 \cdot 10^{-6} \mathrm{~m}^{2} / \mathrm{s}$, бегущие капиллярные волны стержневыми источниками не возбуждаются. На поверхности слоя масла возможно лишь параметрическое возбуждение стоячих волн [9].

Для учета вязкого затухания энергии волн с расстоянием от источника для плотности энергии волн можно ввести множитель $\exp \left[-\alpha\left(r-r_{0}\right)\right]$ $=\exp \left[-4 v k^{2}\left(r-r_{0}\right) / c_{c}\right]$. Поэтому выражение для плотности кинетической энергии частиц поверхности жидкости в среднем в цилиндрической волне примет вид

$$
\bar{w}_{k}=(1 / 4) \rho_{l} v_{0}^{2}\left(r_{0} / r\right) \exp \left[-4 v k^{2}\left(r-r_{0}\right) / c_{c}\right] .
$$

В волнах плотности потенциальной и кинетической энергии равны между собой и плотность $\bar{w}_{p}$ потенциальной энергии в среднем также должна быть равной плотности кинетической энергии в среднем: $\bar{w}_{p}=\bar{w}_{k}$. При этом плотность $\bar{w}$ энергии в среднем в волне равна удвоенной плотности кинетической энергии в среднем

$$
\bar{w}=2 \bar{w}_{k}=(1 / 2) \rho_{l} v_{0}^{2}\left(r_{0} / r\right) \exp \left[-4 v k^{2}\left(r-r_{0}\right) / c_{c}\right] .
$$

Из дисперсионного уравнения капиллярных волн можно получить выражение для плотности энергии в волне $\rho_{l}\left(\omega_{0}^{2} / k^{2}-4 v^{2} k^{2}\right)=\sigma k$, в котором левая и правая части имеют размерности соответственно объемной плотности 
энергии $\left[\mathrm{J} / \mathrm{m}^{3}\right]$ и давления $\left[\mathrm{N} / \mathrm{m}^{2}\right]$. Это выражение указывает на то, что плотность энергии в капиллярной волне по величине равна давлению под свободной поверхностью жидкости с кривизной, равной волновому числу. Для плотности энергии в капиллярной волне вблизи источника запишем уравнение в виде

$$
\rho_{l}\left(\omega_{0}^{2} / k^{2}-4 v^{2} k^{2}\right)+\bar{w}=\sigma(1+\bar{\delta}) k
$$

Отсюда деформация поверхности жидкости при капиллярных колебаниях, возбуждаемых источником, равна отношению плотности энергии, передаваемой жидкости источником, к плотности энергии колебаний в капиллярной волне вдали от источника, где нелинейный вклад источника в энергию волн уже можно не учитывать:

$$
\begin{aligned}
\bar{\delta}= & 2 \bar{w}_{k} / \rho_{l}\left(\omega_{0}^{2} / k^{2}-4 v^{2} k^{2}\right)=(1 / 2)\left[v_{0}^{2} /\left(\omega_{0}^{2} / k^{2}-4 v^{2} k^{2}\right)\right] \\
& \times\left(r_{0} / r\right) \exp \left[-4 v k^{2}\left(r-r_{0}\right) / c_{c}\right] .
\end{aligned}
$$

Максимальная величина деформации, равная

$$
\bar{\delta}=(1 / 2)\left[v_{0}^{2} /\left(\omega_{0}^{2} / k^{2}-4 v^{2} k^{2}\right)\right],
$$

приходится на участок поверхности непосредственно вблизи источника капиллярных колебаний, где $r=r_{0}$. Выражение для деформации можно записать также соотношением

$$
\bar{\delta}=2 \bar{w}_{k} / \sigma k=(2 / \sigma k) \bar{w}_{k 0}\left(r_{0} / r\right) \exp \left[-4 v k^{2}\left(r-r_{0}\right) / c_{c}\right],
$$

где $\bar{w}_{k 0}=(1 / 4) \rho_{l} v_{0}^{2}$. Таким образом, деформация свободной поверхности жидкости капиллярными колебаниями и волнами, возбуждаемыми источником, прямо пропорциональна плотности кинетической энергии, сообщаемой колебаниями частицам поверхности жидкости.

В цилиндрической капиллярной волне деформация поверхности жидкости с расстоянием от источника уменьшается и ее можно представить в виде

$$
\bar{\delta}=\bar{\delta}_{0}\left(r_{0} / r\right) \exp \left[-4 v k^{2}\left(r-r_{0}\right) / c_{c}\right] .
$$

Тогда плотность избыточной поверхностной энергии жидкости в цилиндрической волне равна

$$
\Delta \bar{w}_{s}=\sigma \bar{\delta}_{0}\left(r_{0} / r\right) \exp \left[-4 v k^{2}\left(r-r_{0}\right) / c_{c}\right] .
$$

Плотность потока энергии, переносимой волнами, равна величине вектора Умова (для электромагнитных волн этот вектор принято называть вектором Умова-Пойнтинга): $\mathbf{S}_{U}=w c_{w} \mathbf{n}$, где $w-$ плотность энергии, $c_{w}=d \omega / d k-$ групповая скорость волн, $\mathbf{n}-$ единичный вектор.

Под интенсивностью $I$ волны понимают среднюю величину вектора Умова $I=\bar{w} c_{w}$. Плотность импульса в среднем в волне с фазовой скоростью $c$ при этом равна

$$
\bar{p}=\left(\bar{w} / c^{2}\right) c_{w}=I / c^{2} .
$$

В настоящей работе генерация потоков на поверхности воды осуществляется монохроматическими волнами, имеющими одинаковые фазовую и групповую скорости. Поэтому выражение для плотности потока поверхностной энергии в среднем в цилиндрической капиллярной волне или интенсивности цилиндрической волны можно записать через деформацию поверхности жидкости в виде

$$
I_{s}=\sigma \bar{\delta} c_{c} .
$$

Поток поверхностной энергии $d W_{s} / d t$ вдоль поверхности жидкости на определенном расстоянии $r$ от источника при этом равен произведению плотности потока поверхностной энергии и длины $L$ контура в виде окружности радиуса $r: d W_{s} / d t=I_{s} L$. Так как

$$
I_{s}=\sigma \bar{\delta}_{0}\left(r_{0} / r\right) \exp \left[-4 v k^{2}\left(r-r_{0}\right) / c_{c}\right] c_{c}
$$

и $L=2 \pi r$, поток поверхностной энергии равен

$$
d W_{s} / d t=2 \pi r_{0} \sigma \bar{\delta}_{0} \exp \left[-4 v k^{2}\left(r-r_{0}\right) / c_{c}\right] c_{c} .
$$

Энергию поверхности, перенесенную волной за период $T$ колебаний источника, можно найти из интеграла

$$
d W_{s}=\int_{0}^{T} 2 \pi r_{0} \sigma \bar{\delta}_{0} \exp \left[-4 v k^{2}\left(r-r_{0}\right) / c_{c}\right] c_{c} d t
$$

Она равна

$$
\Delta W_{s}=2 \pi r_{0} \sigma \bar{\delta}_{0} \exp \left[-4 v k^{2}\left(r-r_{0}\right) / c_{c}\right] c_{c} T
$$

и пропорциональна избыточной поверхности $\Delta S=2 \pi r_{0} \bar{\delta}_{0} \lambda_{c}, \quad$ создаваемой источником за период колебаний. Энергия, переносимая волной за период колебаний, равна произведению поверхностного натяжения и избыточной поверхности $\Delta W=\sigma \Delta S$, так как $\lambda_{c}=c_{c} T$. В таком случае волной переносится и избыточная поверхность $S_{\delta}$, поток которой равен

$d S_{\delta} / d t=(1 / \sigma) d W_{s} / d t=2 \pi r_{0} \bar{\delta}_{0} \exp \left[-4 v k^{2}\left(r-r_{0}\right) / c_{c}\right] c_{c}$

и имеет размерность $\left[\mathrm{m}^{2} / \mathrm{s}\right]$. Плотность потока избыточной поверхности при этом равна потоку деформации поверхности с размерностью $[\mathrm{m} / \mathrm{s}]$ :

$$
s_{\delta}=\bar{\delta} c_{c}
$$

Плотность потока поверхностной энергии в среднем при возбуждении источником капиллярных колебаний конечной амплитуды на свободной поверхности жидкости, таким образом, равна произведению коэффициента поверхностного натяжения и потока деформации, создаваемой волнами на поверхности жидкости: $S_{U S}=\sigma s_{\delta}=\sigma \bar{\delta} c_{c}$. Интенсивность потока при этом равна произведению поверхностного натяжения и потока деформации: $\mathbf{I}_{s}=\sigma \mathbf{s}_{\delta}$.

Для плотности импульса волн при этом можно записать уравнение в виде

$$
\bar{p}_{s}=I_{s} / c_{c}^{2}=\left(\sigma / c_{c}^{2}\right) \bar{\delta} c_{c}=\left(\rho_{l} / k\right) \bar{\delta} c_{c} .
$$


В этом выражении отношение плотности жидкости к волновому числу имеет физический смысл поверхностной плотности жидкости $\rho_{s}=\rho_{l} / k$ с размерностью $\left[\mathrm{kg} / \mathrm{m}^{2}\right]$. Тогда плотность поверхностного импульса может быть записана через произведение поверхностной плотности и потока деформации $\bar{p}_{s}=\rho_{s} \bar{\delta} c_{c}=\rho_{s} s_{\delta}$. Размерность плотности поверхностного импульса имеет размерность поверхностного тока $\left[(\mathrm{kg} / \mathrm{s}) / \mathrm{m}=\left(\mathrm{kg} / \mathrm{m}^{2}\right) /(\mathrm{m} / \mathrm{s})\right]$, тогда как поток поверхностного импульса имеет размерность тока жидкости $[\mathrm{kg} / \mathrm{s}]$.

Чтобы написать уравнение движения свободной поверхности жидкости вследствие передачи импульса волн, соотношение для плотности импульса и плотности энергии запишем в виде $\overline{\mathbf{p}}_{s}=\left(\Delta \overline{\mathbf{w}}_{s} / c_{c}^{2}\right) c_{c}$. Производная по времени от плотности импульса при этом равна $d \bar{p}_{s} / d t=\left(1 / c_{c}\right) d \Delta \bar{w}_{s} / d t$. В свою очередь, производная по времени от плотности энергии равна произведению производной плотности энергии по координате и скорости переноса энергии волнами $d \Delta \bar{w}_{s} / d t=\left(\partial \bar{w}_{s} / \partial r\right) d r / d t$. Так как при этом скорость переноса энергии равна скорости волн $d r / d t=c_{c}$, производная по времени от плотности импульса волн оказывается равной $d \bar{p}_{s} / d t=\partial \Delta \bar{w}_{s} / \partial r$. Производную плотности энергии по координате можно выразить как произведение поверхностного натяжения и градиента деформации поверхности волнами: $\partial \Delta \bar{w}_{s} / \partial r=\sigma \operatorname{grad} \bar{\delta}$. Соответственно производная по времени от плотности импульса цилиндрических волн на поверхности жидкости оказывается пропорциональной градиенту деформации поверхности: $d \bar{p}_{s} / d t=\sigma \operatorname{grad} \bar{\delta}$.

Считая, что импульс волн передается частицам поверхности жидкости, можно написать следующее уравнение движения частиц поверхности жидкости:

$$
\rho_{s} d u_{s} / d t=-\sigma \operatorname{grad} \bar{\delta} .
$$

Отсюда ускорение единичной поверхности жидкости вследствие передачи импульса цилиндрических волн равно

$$
d u_{s} / d t=c_{c}^{2} \operatorname{grad} \bar{\delta} .
$$

При этом единичная поверхность жидкости в интервале координат $\Delta r=r_{2}-r_{1}$ от источника приобретает скорость $\Delta u_{s}$, равную

$$
\Delta u_{s}=\left(1 / \rho_{s}\right) \Delta p_{s}=\left[\delta\left(r_{1}\right)-\delta\left(r_{2}\right)\right] c_{c} .
$$

Если отсчет координат вдоль поверхности жидкости вести от источника волн, где $r_{1}=r_{0}$, эта скорость составит $\Delta u_{s}=\delta_{0}\left(1-r_{0} / r\right) c_{c}$.

По определению деформация поверхности жидкости пропорциональна плотности кинетической энергии частиц поверхности, поэтому $\operatorname{grad} \bar{\delta}(2 / \sigma k) \partial \bar{w}_{k} / \partial r$. В свою очередь, градиент поверхностного давления, ускоряющий частицы поверхности жидкости, обусловливается производной плотности кинетической энергии по координате, отсюда $\operatorname{grad}\left(p_{s}\right)=(\sigma k / 2) \operatorname{grad} \bar{\delta}$.

Теперь рассмотрим ток в приповерхностном слое жидкости при наличии цилиндрической капиллярной волны, т. е. в объеме скин-слоя. Плотность кинетической энергии жидкости в среднем в объеме скин-слоя определяется через деформацию поверхности волнами выражением $\bar{w}_{k}=(1 / 2) \sigma k \bar{\delta}$. Разность давления при этом равна разности плотности кинетической энергии частиц жидкости $\Delta p_{V_{s}}=-\Delta \bar{w}_{k}=-(1 / 2) \sigma k \Delta \bar{\delta}$. Отсюда ускорение в слое жидкости, вызванное градиентом давления, равно $d u_{V_{s}} / d t=-\left(1 / \rho_{l}\right) \operatorname{grad}\left(p_{V_{s}}\right)=c_{c}^{2} \operatorname{grad} \bar{\delta}$. Это выражение указывает на то, что из-за градиента деформации поверхности, создаваемого источником капиллярных волн, частицы жидкости в скин-слое приобретают ускорение, пропорциональное квадрату фазовой скорости волн. При этом движение жидкости в скин-слое осуществляется в сторону источника волн. Ускорение частиц поверхности жидкости, обусловленное передачей импульса волн, пропорционально квадрату групповой скорости волн. Ранее экспериментально обнаруженные явления движения слоя жидкости на поверхности вибрирующих стержней и пластин к участкам с пучностями колебаний, где плотность кинетической энергии в среднем частиц жидкости является максимальной, может объясняться и тем, что на этих участках деформация поверхности жидкости также является максимальной.

В случае возбуждения капиллярных волн на свободной поверхности воды двумя синфазно вибрирующими источниками суммарная плотность энергии волн в какой-либо точке поверхности зависит от расстояния от каждого источника, а плотность суммарного импульса волн зависит и от направления.

Рассмотрим свободную поверхность жидкости в декартовой системе координат XОY, где источники расположены на оси ОY (вдоль линии $x=0$ ) на расстоянии $a$ друг от друга, а ось ОХ (линия $y=0$ ) пересекает один из источников (рис. $2, b$ ). Расстояния от источников до точки поверхности с координатами $(x, y)$ равны $r_{1}=\sqrt{x^{2}+y^{2}}$ и $r_{2}=\sqrt{x^{2}+(y-a) y^{2}}$, углы между радиус-векторами $\mathbf{r}_{1}, \mathbf{r}_{2}$ и осью ОХ составляют $\varphi_{1}$ и $\varphi_{2}$.

Так как $r_{1} \geq r_{0}$ и $r_{2} \geq r_{0}$, уравнение для плотности $\Delta \bar{w}_{s}$ избыточной энергии поверхности жидкости при возбуждении волн двумя источниками запишется в виде

$$
\Delta \bar{w}_{s}=\sigma\left(\bar{\delta}_{1}+\bar{\delta}_{0}\right)=\sigma \bar{\delta}_{0}\left(r_{0} / r_{1}+r_{0} / r_{2}\right)
$$

при этом плотность импульса волн в областях поверхности жидкости $y \leq 0$ и $y \geq a$ равна

$$
\bar{p}_{s}=\rho_{s} \bar{\delta}_{0} r_{0}\left[1 / r_{1}+\left(1 / r_{2}\right) \cos \left(\varphi_{1}-\varphi_{2}\right)\right] c_{c} .
$$

В области поверхности $0 \leq y \leq a$ импульсы волн направлены противоположно друг к другу и плотность импульса равна

$$
\bar{p}_{s}=\rho_{s} \bar{\delta}_{0} r_{0}\left[1 / r_{1}-\left(1 / r_{2}\right) \cos \left(\varphi_{1}+\varphi_{2}\right)\right] c_{c} .
$$

Анализ уравнений для плотности импульса волн указывает на то, что ее величина является максимальной на участках поверхности жидкости $y \leq 0$ и $y \geq a$ вдоль линии, пересекающей источники волн. Соответственно 
наблюдаемые поверхностные течения обусловлены передачей импульса волн частицам поверхности жидкости.

Деформация поверхности жидкости волнами от двух источников равна

$$
\bar{\delta}=\bar{\delta}_{0}\left(r_{0} / r_{1}+r_{0} / r_{2}\right)
$$

и является также максимальной вдоль линии, пересекающей источники. Поэтому градиент этой деформации обусловливает движение скин-слоя жидкости в направлении, перпендикулярном этой линии. Эти ускорения жидкости, направленные в сторону источников, максимальны вдоль линий $y=0$ и $y=a$.

Картина экспериментально наблюдаемых поверхностных течений при возбуждении капиллярных волн на поверхности воды распределенными источниками, таким образом, указывает на генерацию поверхностных течений капиллярными волнами за счет передачи импульса волн частицам поверхности воды. Так как плотность импульса волн является пропорциональной потоку деформации поверхности, волнами переносится избыточная поверхность, периодически создаваемая источниками капиллярных колебаний.

При интерференции волн одинаковой частоты и соответственно одинаковой длины $\lambda_{c}$, исходящих от двух источников, разнесенных на расстояние $a$, равное или кратное половине длины волны $a=n\left(\lambda_{c} / 2\right)$, на участке поверхности воды между источниками возбуждаются капиллярные колебания в виде стоячей волны. За пределами этого участка поверхности воды капиллярные колебания распространяются в виде бегущих волн, которые передают импульс частицам воды на ее свободной поверхности. При этом суммарная плотность импульса интерферирующих капиллярных волн на поверхности воды оказывается максимальной вдоль линии, соединяющей источники, по обе стороны от источников, где и наблюдается поверхностный поток с максимальной скоростью. В капиллярных колебаниях в виде стоячей волны между концами стержней перенос энергии и импульса отсутствует. Однако на этом участке поверхности воды амплитуда капиллярных колебаний, плотность кинетической энергии частиц жидкости и соответственно деформация свободной поверхности больше по сравнению с другими участками. Так как плотностью кинетической энергии определяется гидродинамическое давление в жидкости, в ней создается градиент давления, ускоряющий частицы приповерхностного слоя жидкости в область между вибрирующими концами стержней. Этот градиент давления определяется также градиентом деформации поверхности в среднем. В результате на поверхности воды возникают плоские струйные течения. Таким образом, капиллярные волны, возбуждаемые двумя синфазно вибрирующими источниками, переносят избыточную поверхность, создаваемую источниками в результате локальной деформации поверхности, и создают разнонаправленные поверхностные потоки.
В экспериментах также заметно, что поверхностные течения стремятся локализоваться вдоль линии, пересекающей источники капиллярных колебаний. Это объясняется двумя причинами. Во-первых, течения вдоль поверхности воды можно рассматривать как трубки тока, в которых гидродинамическое давление пропорционально квадрату осредненной скорости, сообщаемой частицам поверхности жидкости в результате передачи импульса капиллярных волн. Соответственно в приповерхностном слое жидкости создается градиент давления, равный градиенту гидродинамического давления, вследствие которого частицы поверхности жидкости получают ускорение в сторону течений с большей осредненной скоростью и соответственно с большей плотностью импульса капиллярных волн. Так как плотность кинетической энергии в капиллярной волне прямо пропорциональна деформации свободной поверхности жидкости, явление сужения поверхностного потока можно объяснить наличием градиента деформации поверхности жидкости. Ускорения частиц жидкости в поверхностном потоке можно найти из выражения

$$
\mathbf{d u} / \mathbf{d t}=c_{c}^{2}[(\partial \bar{\delta} / \partial x) \mathbf{i}+(\partial \bar{\delta} / \partial y) \mathbf{j}] .
$$

Во-вторых, частицы жидкости в поверхностном потоке с меньшей скоростью должны получить ускорение в сторону потока с большей скоростью также из-за вязкости жидкости.

\section{3. Поверхностные потоки на поверхности воды в каналах при возбуждении капиллярных колебаний синфазно вибрирующими источниками}

С целью получения направленного поверхностного потока, создаваемого капиллярными волнами на поверхности воды в чашке Петри, часть поверхности воды ограничивалась каналом, в котором свободная поверхность воды для капиллярных волн представляет собой волновод. Стенки канала образованы двумя пластинами шириной $5 \mathrm{~mm}$ и толщиной $0.1 \mathrm{~mm}$, загнутыми с одной стороны в U-образной форме. Пластины приклеены на основание или присоединены перемычкой зеркально-симметрично U-образными частями напротив друг друга, между которыми оставлена щель. Ширина щели равна ширине U-образных частей пластин и составляет $5 \mathrm{~mm}$. Устройство устанавливалось на дно чашки Петри, в которую наливалась вода так, чтобы ее свободная поверхность не смачивала верхние края пластин. При этом в чашке Петри создавался канал, полностью открытый с одного конца и имеющий на другом конце две U-образные полости, разделенные узким входным каналом. Возбуждение капиллярных колебаний и волн в канале осуществлялось стержневыми осцилляторами, для этого концы стержней пьезоэлектрического осциллятора подводились к поверхности воды напротив центров U-образных полостей в канале. Для определенных частот капиллярных колебаний часть свободной 


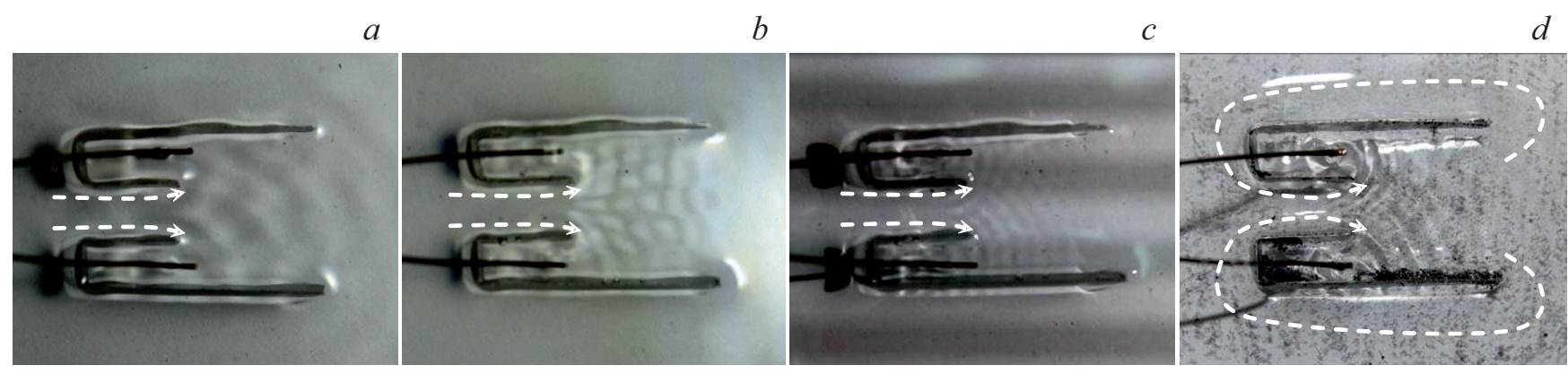

Рис. 3. Капиллярные волны и поток на поверхности воды в канале от двух источников, синфазно вибрирующих с частотой 42 (a), $130(b), 255(c)$ и $144 \mathrm{~Hz}(d)$.

поверхности воды, ограниченная U-образной полостью, представляет собой четвертьволновой резонатор из-за отражения волн от закрытой стороны полости. Соответственно U-образные части канала можно назвать резонаторами.

Экспериментами установлено, что при определенных частотах вибрации стержней на поверхности воды в плоском канале возникает картина распределенных двумерных капиллярных волн, исходящих в направлении от открытых сторон U-образных полостей резонаторов и распространяющихся вдоль канала в одном направлении. Двумерные бегущие волны с поперечной составляющей в виде стоячей волны образуются в результате интерференции волн. Засеивание поверхности воды в канале трассерными частицами показывает, что в канале создается поверхностный поток жидкости, направленный вовнутрь канала через щель между резонаторами, где волны отсутствуют. Движение потока с максимальной скоростью наблюдается в случае, когда частота вибраций стержней соответствует условию возбуждения капиллярных волн, полудлина которых равна или кратна ширине полости U-образных резонаторов. Кроме этого, на скорость движения частиц жидкости в потоке влияет положение концов стержней в полости U-образных резонаторов. Для создания эффективного потока в канале расстояние от конца стержня до задней стенки в каждом U-образном резонаторе должно быть кратным четверти длины капиллярной волны. Таким образом, направленное движение поверхностного потока жидкости осуществляется двумерными капиллярными волнами, возбуждаемыми в канале синфазно вибрирующими источниками капиллярных колебаний напротив U-образных полостей четвертьволновых резонаторов капиллярных волн. Трассерные частицы, движущиеся в канале вместе с потоком, позволяют выявить ускорение потока вблизи краев U-образных полостей резонаторов (рис. 3, $a-c$ ). Траектории движения частиц также показывают, что поток в канале образует поверхностные токи, замкнутые через поверхность воды снаружи устройства (рис. 3,d). В области волнового возмушения в широкой части канала траектории движения частиц являются хаотическими и двумерными, при этом их движение в среднем вдоль направления распространения волн сохраняется.

Поверхностные потоки на поверхности воды были получены также с помощью волноводной конструкции $16 \times 28 \mathrm{~mm}$, содержащей 4 четвертьволновых резонатора и 3 щели между резонаторами. Полости резонаторов и щели имеют размеры $4 \times 5 \mathrm{~mm}$. Синфазное возбуждение капиллярных колебаний осуществлялось стержневыми осцилляторами, подведенными к свободной поверхности воды в центре полости четвертьволновых резонаторов, расстояние между которыми составляло $8 \mathrm{~mm}$. Осцилляторы приклеены к краю волновода в виде РЕТ пластины размером $36 \times 10 \times 0.3 \mathrm{~mm}$, а вибрации самой пластины возбуждались пьезоэлектрическим преобразователем FML-27T-3.9A1-100. На рис. 4 показана картина двумерных капиллярных волн, возбуждаемых при различных частотах в относительно широком канале $28 \mathrm{~mm}$, содержащем 4 четвертьволновых резонатора и 4 осциллятора. Вблизи резонансных частот капиллярных колебаний в устройстве генерируются поверхностные потоки воды, в которых движение частиц воды происходит через открытые каналы - щели между резонаторами в направлении участка поверхности воды, возмущенного двумерными волнами. В области участка поверхности воды с волновым возмущением наблюдаются также вторичные вихревые течения.

Движущийся поток частиц слоя жидкости в канале несет импульс. Соответственно в силу законов сохранения возможно получение движения незакрепленного устройства с каналом на поверхности жидкости в обратном направлении к потоку в канале.

Устройство с капиллярно-волновым движителем (рис. 5,a) содержит корпус из пустотелых полимерных цилиндров диаметром $12 \mathrm{~mm}$ и длиной $75 \mathrm{~mm}$. Цилиндры установлены параллельно и склеены металлическими скобами с зазором шириной $15 \mathrm{~mm}$ между ними. К цилиндрам в зазоре симметрично приклеены загнутые пластины L-образной формы шириной $8 \mathrm{~mm}$, длинные стороны пластин и обращенные к ним стороны цилиндров образуют U-образные полости размером $12 \times 5 \mathrm{~mm}$. Между пластинами оставлена щель шириной $5 \mathrm{~mm}$. На корпусе устройства установлен пьезоэлек- 

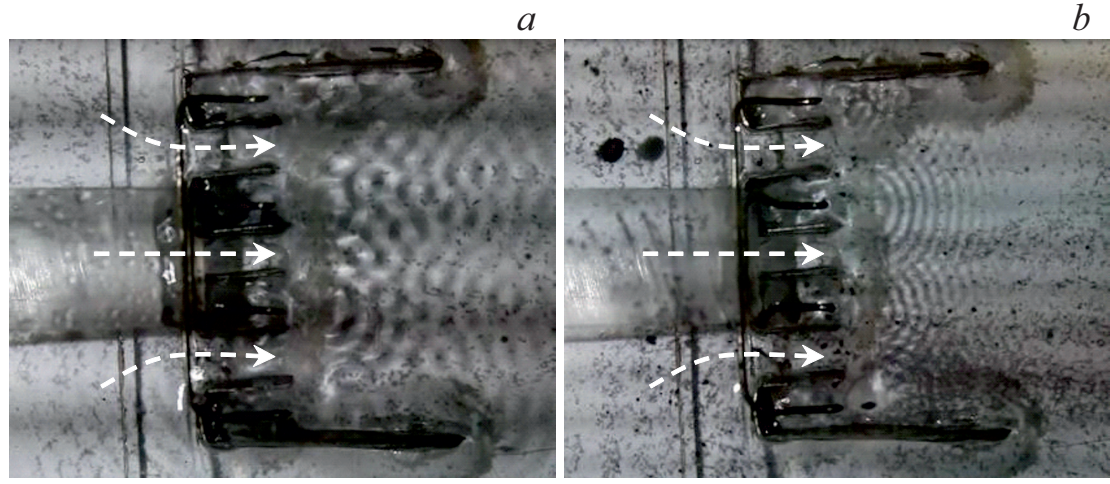

$b$

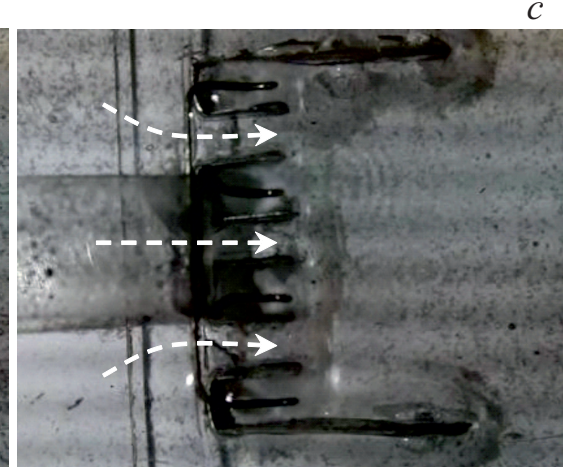

Рис. 4. Капиллярные волны и потоки на поверхности воды в канале от четырех источников капиллярных колебаний, вибрирующих с частотой $252(a), 670(b)$ и $3.9 \mathrm{kHz}(c)$.
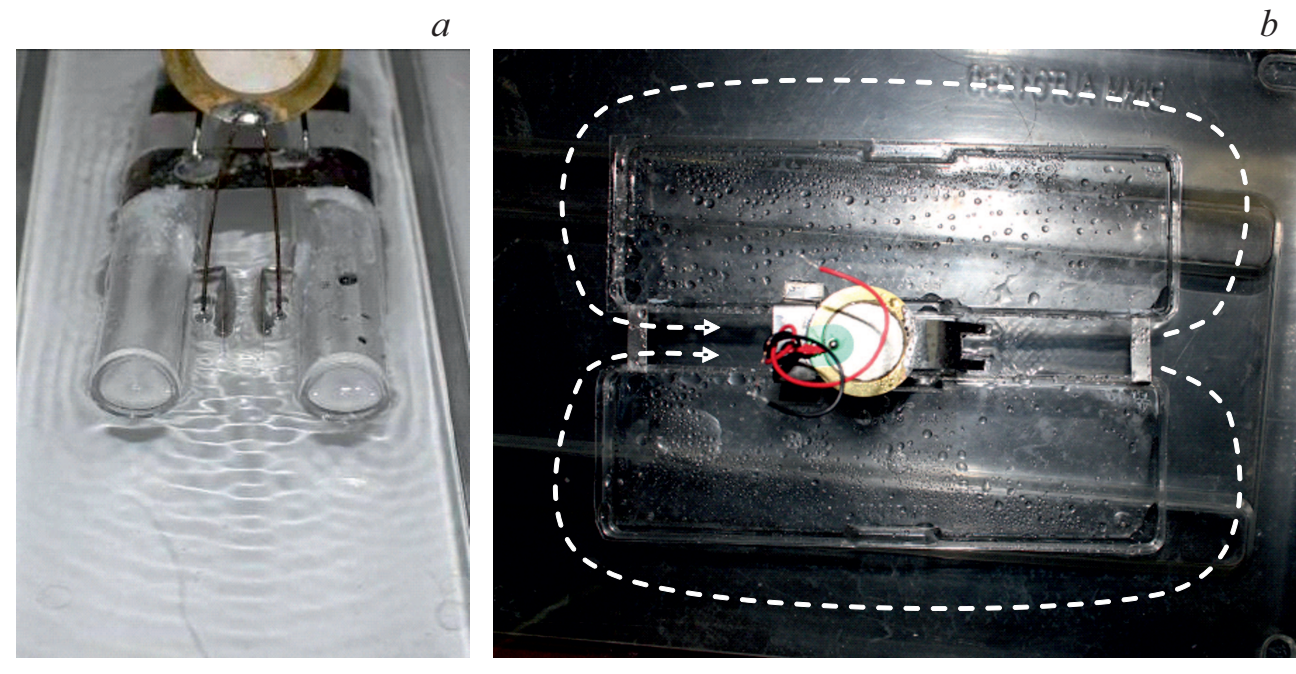

Рис. 5. Устройства с капиллярно-волновым движителем при возбуждении волн частотой 137 (a) и $212 \mathrm{~Hz}(b)$.

трический преобразователь FML-27T-3.9A1-100 с двумя осцилляторами из металлических стержней диаметром $0.6 \mathrm{~mm}$ и длиной $30 \mathrm{~mm}$. Свободные концы стержней подведены в U-полости к их открытым сторонам. Электроды пьезопреобразователя присоединены гибкими тонкими проводами к вторичной обмотке выходного трансформатора усилителя сигналов генератора низкой частоты. При размещении устройства на поверхность воды его корпус смачивается водой, при этом зазор образует сквозной канал между цилиндрами. Загнутые пластины в зазоре ограничивают часть поверхности воды, образуя полости четвертьволновых резонаторов капиллярных волн. При этом свободные концы стержней касаются поверхности воды в полости резонаторов, обеспечивая капиллярный подъем воды. При подаче на электроды пьезопреобразователя переменного напряжения частотой $137 \mathrm{~Hz}$ стержни вибрируют на одной из резонансных частот капиллярных колебаний и возбуждают двумерные бегущие волны в канале, которые создают направленный поверхностный поток воды. При напряжении амплитудой $20 \mathrm{~V}$ на электродах пьезопреобра- зователя устройство общим весом $8 \cdot 10^{-3} \mathrm{~kg}$ движется со скоростью $20 \mathrm{~mm} / \mathrm{s}$. Амплитуда колебаний концов стержней в контакте с водой не превышает $0.1 \mathrm{~mm}$.

$\mathrm{C}$ целью исследования процессов образования направленного потока в канале синфазно вибрирующими источниками капиллярных волн изготовлено устройство с капиллярно-волновым движителем (рис. 5, $b$ ), подобное катамарану. Его корпус собран из двух полимерных лотков прямоугольной формы $145 \times 45 \times 8 \mathrm{~mm}$, соединенных параллельно с зазором шириной $15 \mathrm{~mm}$ между ними. На противоположных сторонах зазора к лоткам приклеены загнутые пластины L-образной формы, длинные стороны пластин и обращенные к ним стороны лотков образуют U-образные полости размером $10 \times 5 \mathrm{~mm}$. Между пластинами оставлена щель шириной $5 \mathrm{~mm}$. На корпусе устройства установлен пьезоэлектрический преобразователь FML-27T-3.9A1-100 с пластинчатым волноводом шириной $12 \mathrm{~mm}$ и толщиной $0.1 \mathrm{~mm}$, от свободного волновода отведены два коротких осциллятора шириной $2 \mathrm{~mm}$. Вес устройства составляет $16 \cdot 10^{-3} \mathrm{~kg}$. При помещении устройства на поверхность воды его 

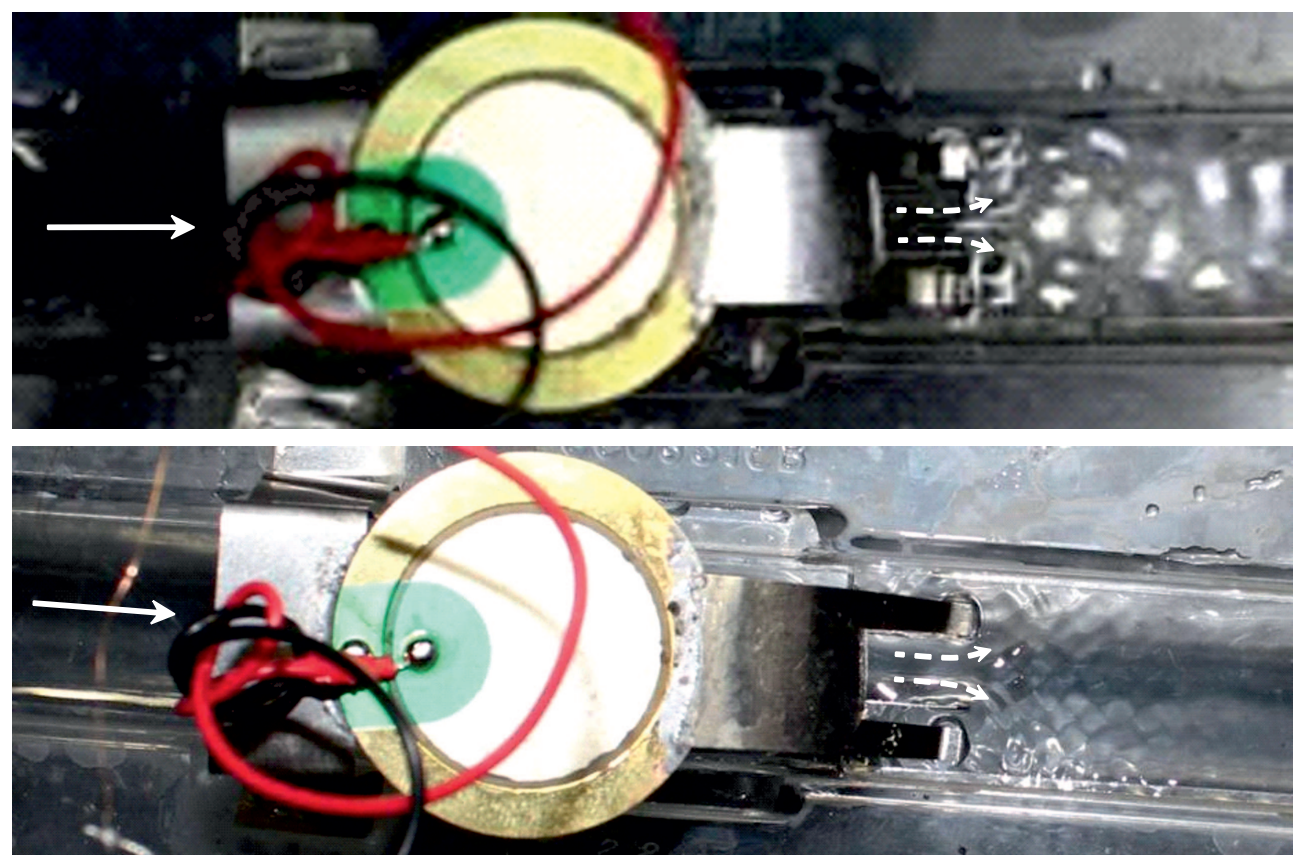

Рис. 6. Картина двумерных капиллярных волн в канале движущегося устройства при частотах 76 (сверху) и $214 \mathrm{~Hz}$ (внизу).

корпус смачивается водой и между лотками образуется канал, свободная поверхность воды в котором для капиллярных волн представляет волновод, ограниченный шириной канала.

При подключении устройства к источнику переменного тока при определенных частотах возбуждения осцилляторов устройство возбуждает в канале бегущую капиллярную волну с распределенной амплитудой, в результате чего в канале создается направленный поток. При этом устройство движется в противоположном потоку направлении в канале. Засеивание поверхности воды трассерными частицами показало, что поток, выходящий из канала, разделяется на два замкнутых потока, огибающих корпус устройства и входящих в канал с противоположной стороны. Движения устройства наблюдались также и при других частотах $(616,704 \mathrm{~Hz})$ возбуждения волн, но из-за малости их амплитуды эти волны практически не заметны. При подаче на электроды пьезопреобразователя электрического напряжения частотой $3.5 \mathrm{kHz}$ устройство приобретает достаточно большую скорость в $60 \mathrm{~mm} / \mathrm{s}$, но это уже связано с возбуждением резонансных колебаний самого преобразователя и образованием струй воды, исходящих из-под краев осцилляторов.

На рис. 6 представлена картина двумерных волн частотой 76 и $214 \mathrm{~Hz}$ в канале устройства с двумя источниками синфазных капиллярных колебаний. Сплошной стрелкой показано направление движения поверхностного потока на невозмущенном волнами участке свободной поверхности воды в канале. Прерывистыми стрелками - части траекторий движения трассерных частиц в потоке вблизи краев U-образных полостей четверть- волновых резонаторов капиллярных колебаний. Засеивание поверхностного потока воды в канале устройства трассерными частицами и наблюдение за траекторией движения этих частиц показало, что ускорение частиц в потоке происходит вблизи краев полостей четвертьволновых U-образных резонаторов капиллярных волн. При указанных частотах возбуждения волн средние скорости движения частиц на участке с невозмущенной свободной поверхностью воды оценивались примерно в 15 и $20 \mathrm{~mm} / \mathrm{s}$, а скорости движения устройства составили 2 и $3 \mathrm{~mm} / \mathrm{s}$.

Таким образом, устройство получает движение вследствие возбуждения капиллярных колебаний двумя синфазно вибрирующими источниками и образования в канале направленного поверхностного потока воды. Осцилляторы синфазно возбуждают капиллярные колебания на свободной поверхности воды в канале напротив открытых полостей U-образных резонаторов, периодически локально деформируя поверхность воды. Капиллярные колебания на поверхности воды в дальнейшем распространяются в виде волн, бегущих вдоль канала в сторону от открытых сторон U-образных резонаторов и создающих поток деформации и соответственно поток избыточной поверхности. Щель между четвертьволновыми резонаторами в канале обеспечивает непрерывность свободной поверхности жидкости, через которую затягивается поверхность жидкости при ее деформации осцилляторами. При определенных частотах электрического напряжения на электродах пьезоэлектрического преобразователя осцилляторы возбуждают капиллярные волны длиной, кратной удвоенной ширине полости четвертьволновых резонаторов и соответственно удвоенной 




$b$

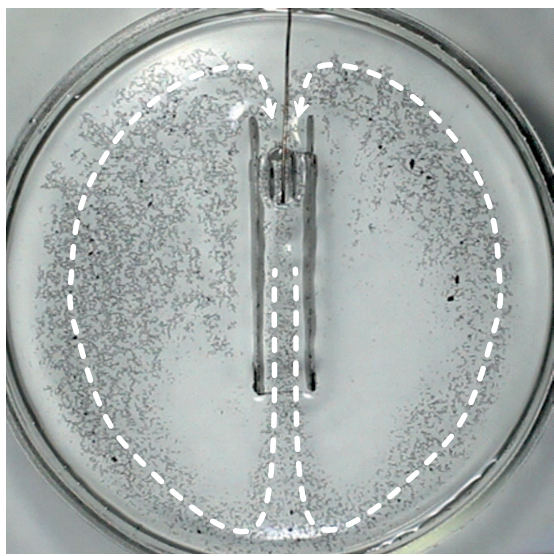

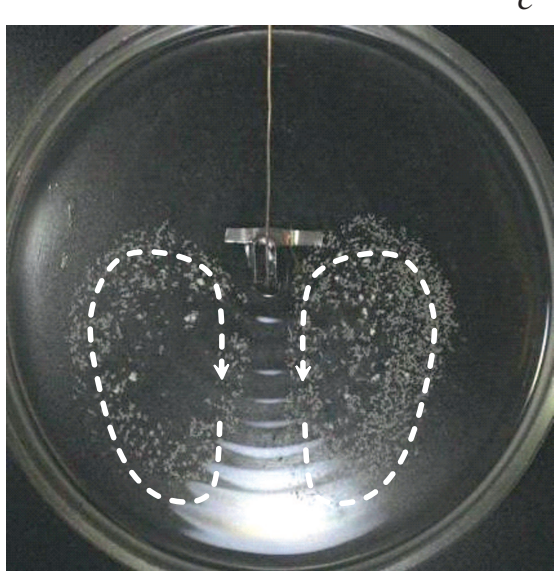

Рис. 7. Картина волн и течений, создаваемых на поверхности воды источником и резонатором, расположенными в коротком $(a)$ и длинном $(b)$ каналах и одним источником и резонатором $(c)$.

ширине щели в канале между резонаторами. При этом в результате интерференции и отражения от стенок канала волны создают двумерную распределенную бегущую волну, которая имеет в канале поперечную составляющую в виде стоячей волны. В результате поверхностный поток в канале, создаваемый волнами за счет переноса энергии, деформации и избыточной поверхности, усиливается.

\section{4. Потоки в каналах с одним источником капиллярных волн и одним резонатором}

Дальнейшие исследования показали, что генерация поверхностного потока воды возможна также в каналах с одним источником капиллярных колебаний и одним четвертьволновым резонатором, установленными в центре канала. В конструкции канала между стенками канала и резонатора оставлены щели шириной, равной ширине полости резонатора. В целом для капиллярных волн свободная поверхность воды в таком канале представляет собой отрезок волновода, содержащий в центре четвертьволновой резонатор. На рис. 7, $а$ показана картина волн и течений на поверхности воды в чашке Петри при возбуждении капиллярных колебаний частотой $56 \mathrm{~Hz}$ на участке поверхности воды, ограниченном каналом размером $28 \times 12 \mathrm{~mm}$, в котором стержневой источник капиллярных колебаний расположен напротив открытой полости U-образного резонатора размером $8 \times 4 \mathrm{~mm}$ в центре канала. Как видно, капиллярные колебания в канале распространяются только в одном направлении в виде бегущей волны, создавая общий поверхностный поток воды. Траектории движения трассерных частиц указывают на то, что поток состоит из двух плоских течений, ускорение частиц в которых происходит на участках поверхности воды непосредственно вблизи краев резонатора капиллярных колебаний. Токи в этих течениях замыкаются за пределами конструкции канала. Кроме того, на поверхности воды также наблюдаются вторичные вихревые течения, расположенные по двум сторонам потока, исходящего из канала.

В устройстве с длинным каналом $50 \times 10 \mathrm{~mm}$ и резонатором с полостью $3.5 \times 8 \mathrm{~mm}$ интерференционная картина волн в основном заметна на поверхности воды в самом канале, а течения проходят через весь канал и замыкаются снаружи канала (рис. 7,b). Устройство с одним источником и резонатором с полостью $4 \times 8 \mathrm{~mm}$, не ограниченное каналом (рис. 7,c), возбуждает полуцилиндрические волны и вихревые течения, подобные тем, которые наблюдаются на одной из половин поверхности воды в чашке Петри при возбуждении волн двумя синфазно вибрирующими источниками (рис. 2, $a$ ).

Капиллярные волны, возбуждаемые стержнем и резонатором в канале, являются полуцилиндрическими. В результате отражения волн от стенок канала на поверхности воды в канале происходит их интерференция, линии гребней в них искажаются ускоряющимся потоком (рис. 8). Так как в центральной части потока скорость жидкости максимальная, линии гребней волн в центре потока заостряются.

Картина волн и течений, аналогичная наблюдаемой на ограниченной поверхности воды в чашке Петри, возникает и на больших практически не ограниченных поверхностях. Так, на рис. 9, $a$ показаны волны и течения, формируемые источником капиллярных волн в канале с резонатором на площади свободной поверхности воды $80 \times 210 \mathrm{~mm}$. Свободная поверхность воды в коротком канале размером $12 \times 22 \mathrm{~mm}$ с установленным в нем резонатором $4 \times 8 \mathrm{~mm}$ и источником капиллярных колебаний (рис. 9, $b$ ) при этом представляет собой отрезок волновода для капиллярных бегущих волн определенной частоты.

Эксперименты с возбуждением капиллярных колебаний на поверхности воды в чашке Петри, приводящих к образованию поверхностных потоков, проводились также с помощью источника и четвертьволнового резонатоpa, установленных в круговом канале шириной $15 \mathrm{~mm}$, 

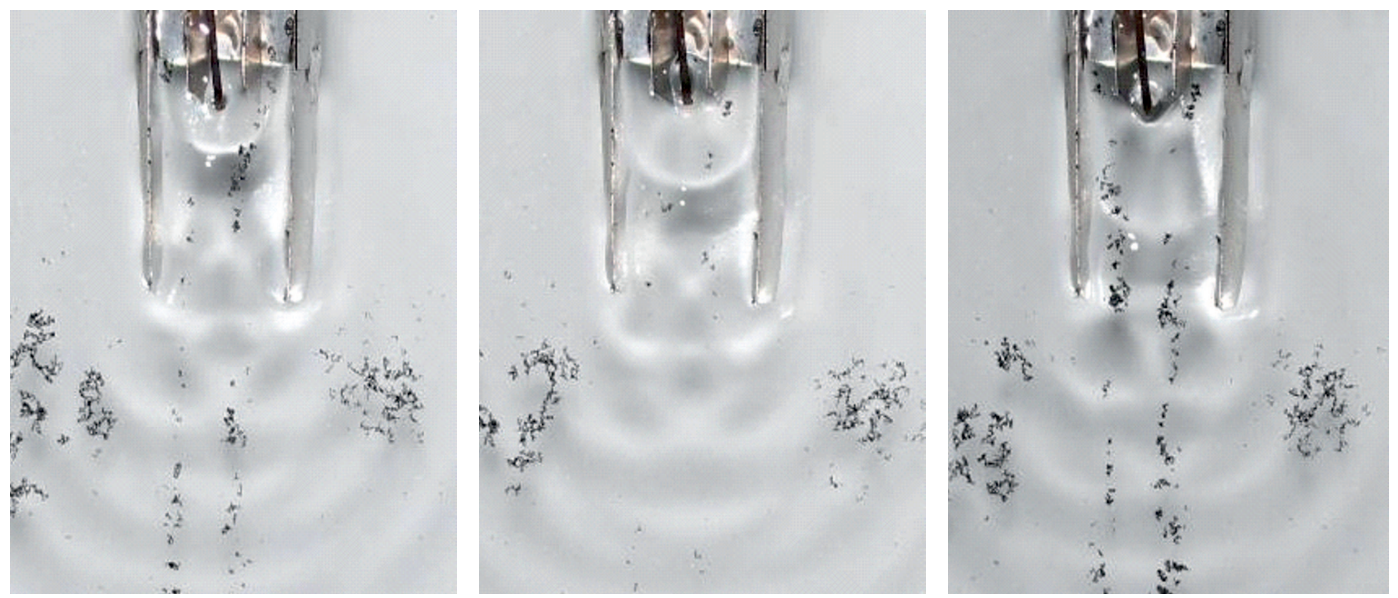

Рис. 8. Картина волн и поверхностных потоков на поверхности воды, возбуждаемых стержнем, вибрирующим с частотой $56 \mathrm{~Hz}$ в канале с одним резонатором.

$a$

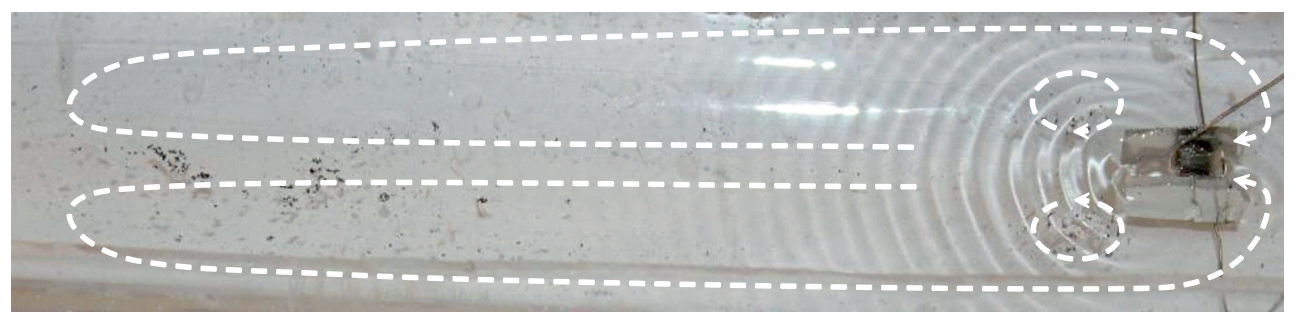

$b$

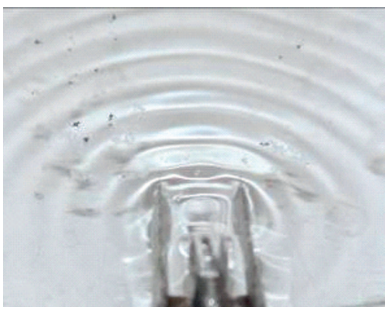

Рис. 9. Волны и течения на большой поверхности воды, создаваемые одним источником и резонатором в открытом канале.

$a$
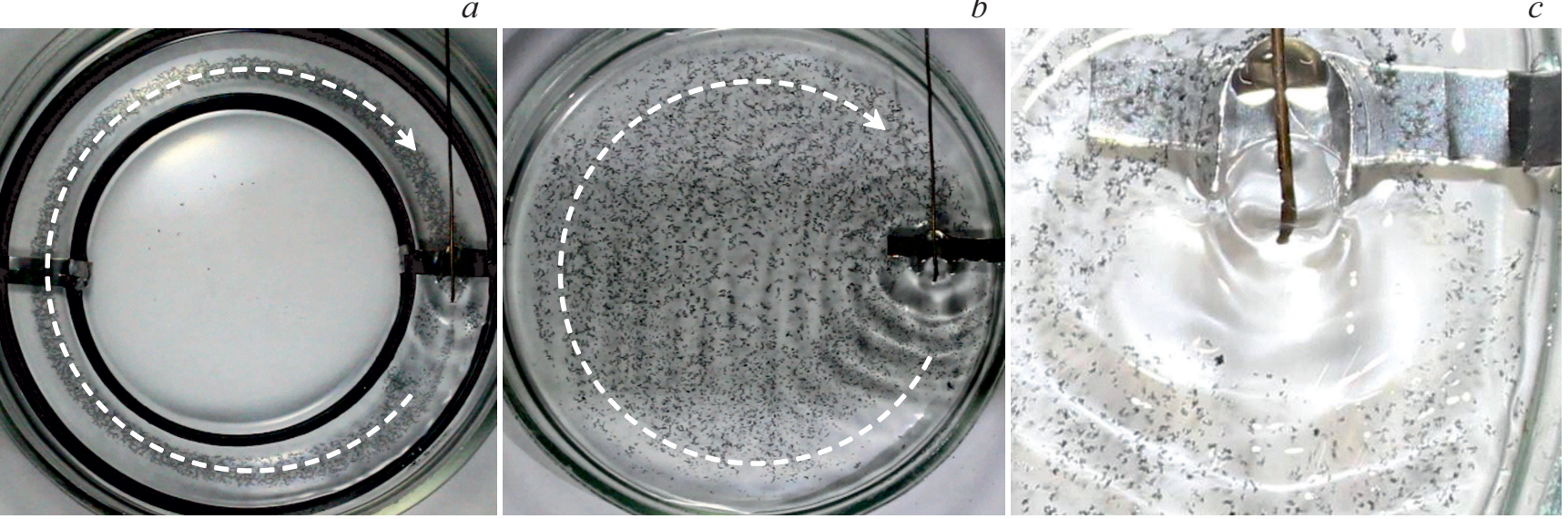

Рис. 10. Волны и течения в круговом канале $(a)$, на круглой поверхности воды $(b)$ и вблизи четвертьволнового резонатора $(c)$, создаваемые источником, вибрирующим с частотой $56 \mathrm{~Hz}$.

ограниченном цилиндрическими кольцами. Кольца шириной $10 \mathrm{~mm}$ вырезаны из полимерных труб и размещены в чашке Петри с водой. Свободная поверхность воды, ограниченная кольцами, при этом представляет собой замкнутый волновод для капиллярных волн. При возбуждении капиллярных колебаний стержневым осциллятором напротив U-образной полости четвертьволно- вого резонатора размером $5 \times 5 \mathrm{~mm}$ колебания в канале распространяются в виде волн и создают непрерывный замкнутый поток (рис. 10,a). При частоте колебаний осциллятора $56 \mathrm{~Hz}$ скорость потока в канале составила $18 \mathrm{~mm} / \mathrm{s}$. Также оказалось возможным образование поверхностного потока, вовлекающего во вращательное движение всю поверхность воды в чашке Петри, при 


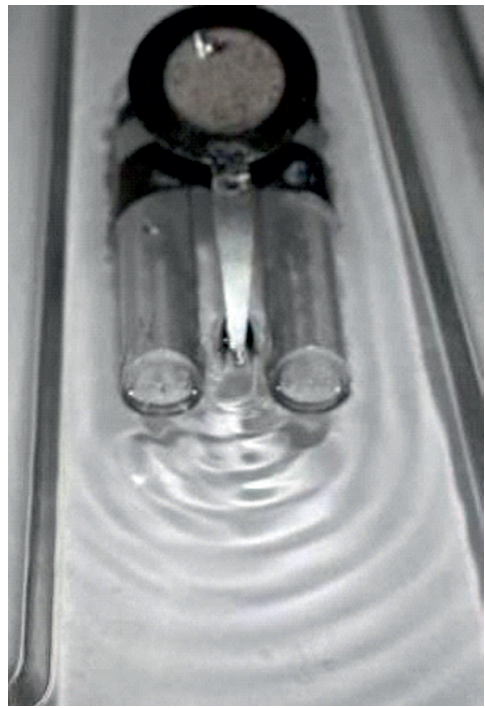

$b$

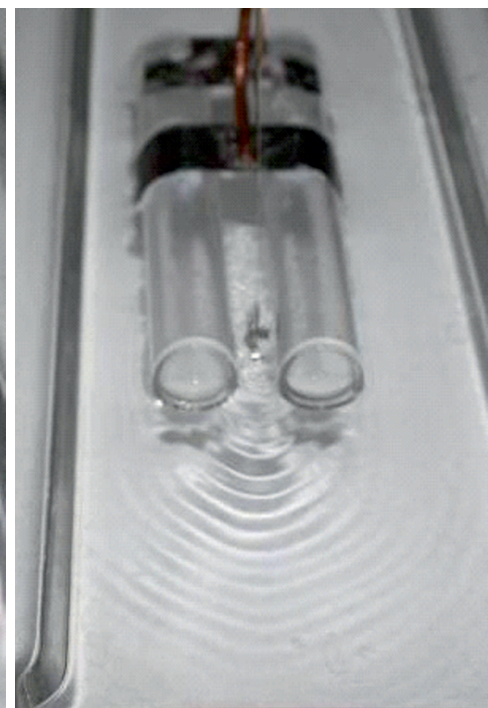

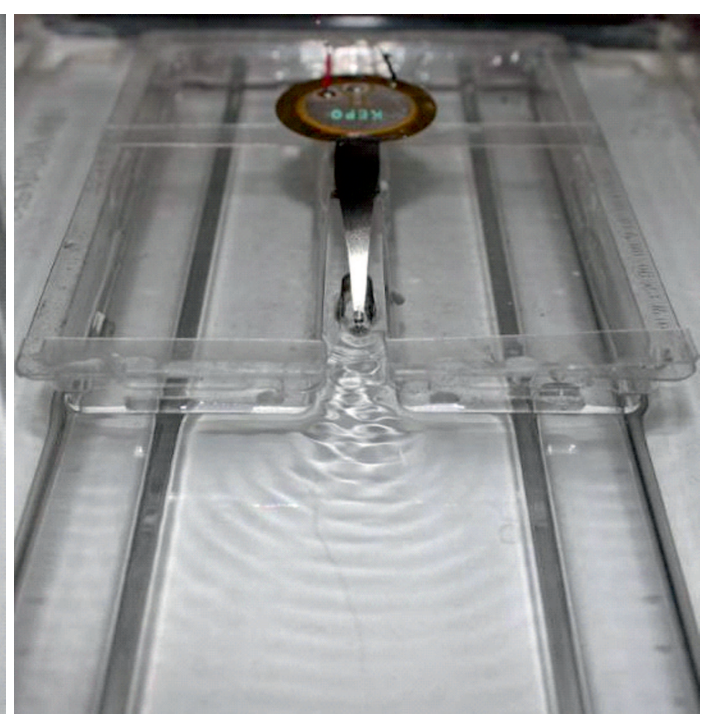

Рис. 11. Картина двумерных капиллярных волн, создаваемая движущимися устройствами с одним источником и одним резонатором капиллярных колебаний при частотах возбуждения $46(a), 280(b)$ и $58 \mathrm{~Hz}(c)$.

расположении четвертьволнового резонатора и источника капиллярных колебаний вблизи внутренней стенки чашки (рис. 10,b). Для этого между стенкой чашки и резонатором оставлялась щель шириной, примерно равной ширине полости резонатора. Средняя скорость поверхностного потока вблизи стенки чашки Петри при частоте вибраций источника $56 \mathrm{~Hz}$ составила $16 \mathrm{~mm} / \mathrm{s}$. На увеличенном изображении поверхности воды вблизи полости четвертьволнового резонатора (рис. 10, c) заметны симметрично расположенные пучности капиллярных колебаний, исходящих также от краев U-образного резонатора, что указывает на колебания краев резонатора. Это связано с тем, что источник имеет достаточно большую амплитуду колебаний для параметрического возбуждения капиллярных колебаний, приводящих к локальной деформации свободной поверхности жидкости.

Для получения движения от поверхностного потока, создаваемого одним источником и одним резонатором в канале, изготовлены устройства с капиллярноволновым ускорителем потока (рис. 11). Устройство весом $8 \cdot 10^{-3} \mathrm{~kg}$ с корпусом из пустотелых цилиндров, ширина канала между которыми составляет $10 \mathrm{~mm}$, с пьезопреобразователем 7NB-31R2DM-1 и пластинчатым вибратором, свободный край которого расположен напротив полости четвертьволнового резонатора капиллярных волн в канале, показано на рис. 11, $a$. Устройство при расположении на поверхности воды получает движение от потока в канале, создаваемого капиллярными волнами, возбужденными вибрирующим краем пластины. При подаче на электроды пьезопреобразователя переменного напряжения амплитудой $20 \mathrm{~V}$ и частотой $46 \mathrm{~Hz}$ устройство движется со скоростью $8 \mathrm{~mm} / \mathrm{s}$. Во втором устройстве с таким же весом (рис. $11, b$ ) канал имеет ширину $5 \mathrm{~mm}$, четвертьволновой резонатор отсутствует, пьезопреобразователь FML-20T-6.0A1-100 и стальная пластина, свободный торцевой край которой касается поверхности воды, расположены в вертикальной плоскости. При подаче на электроды пьезопреобразователя переменного напряжения частотой $280 \mathrm{~Hz}$ пластина возбуждает резонансные капиллярные колебания вследствие отражения волн от стенок канала. В результате формируется бегущая распределенная волна, создающая однонаправленный поверхностный поток воды в канале. При напряжении амплитудой $25 \mathrm{~V}$ на электродах пьезопреобразователя скорость движения устройства составляет $22 \mathrm{~mm} / \mathrm{s}$.

На рис. 11, с показано устройство на платформе из прямоугольных лотков $145 \times 45 \times 8 \mathrm{~mm} \mathrm{c} \mathrm{зазором} \mathrm{ши-}$ риной $15 \mathrm{~mm}$ между ними. Устройство весом $18 \cdot 10^{-3} \mathrm{~kg}$ содержит пьезопреобразователь FT-35T-2.8BL, пластинчатый волновод длиной $45 \mathrm{~mm}$, свободный торцевой край которого имеет ширину $2 \mathrm{~mm}$, и U-образный резонатор $10 \times 5 \mathrm{~mm}$. При размещении устройства на поверхности воды и подаче на электроды пьезопреобразователя переменного напряжения амплитудой $20 \mathrm{~V}$ и частотой $58 \mathrm{~Hz}$ скорость движения устройства составляет $10 \mathrm{~mm} / \mathrm{s}$, скорость поверхностного потока в канале $30 \mathrm{~mm} / \mathrm{s}$.

Практические приложения явления генерации поверхностного потока жидкости в каналах с источником и резонатором капиллярных колебаний вследствие малой интенсивности капиллярных волн могут ограничиваться малыми объемами жидкости. Эти явления могут представлять интерес тем, что на их основе возможно создание технических устройств, генерирующих управляемые поверхностные потоки жидкости. Принцип действия движителей с капиллярно-волновым ускорителем потока в канале, свободная поверхность жидкости в котором 
для капиллярных волн представляет волновод возможно найдет приложение для разработки технических средств, содержащих волноводы со встроенными в их полости резонаторами и источниками акустических и электромагнитных колебаний.

\section{Заключение}

Таким образом, генерация направленного потока на поверхности жидкости в каналах с резонаторами и источниками капиллярных колебаний может быть объяснена локальной деформацией свободной поверхности жидкости источником капиллярных колебаний, при котором образуется искривленная избыточная поверхность, и переносом этой поверхности волнами. Капиллярные волны c поперечной составляющей в виде стоячей волны, бегущие вдоль поверхности жидкости в канале, вместе с потоком энергии переносят избыточную поверхность, плотность потока которой равна потоку деформации поверхности в волне. В результате на поверхности жидкости в каналах образуется осредненный поток.

\section{Конфликт интересов}

Автор заявляет, что у него нет конфликта интересов.

\section{Список литературы}

[1] В.А. Александров, А.И. Карпов. Химическая физика и мезоскопия, 21 (3), 345 (2019). DOI: $10.15350 / 17270529.2019 .3 .37$

[2] Д.В. Любимов, Т.П. Любимова, А.А. Черепанов. Динамика поверхностей раздела в вибрационных полях (Физматлит, М., 2003)

[3] S. Shklyaev, A.A. Alabuzhev, M. Khenner. Phys. Rev. E., 92, 013019 (2015). DOI: 10.1103/PhysRevE.92.013019

[4] Ю.Д. Чашечкин. ПММ., 83 (3), 403 (2019). DOI: $10.1134 /$ S0032823519030032 [Yu.D. Chashechkin. Fluid Dyn., 54 (7), 919 (2019). DOI: $10.1134 / \mathrm{S} 00154628$ 19070036]

[5] А.Ю. Ильиных. ПММ, 83 (3), 413 (2019). DOI: 10.1134/S0032823519030056 [A.Yu. Ilinykh. Fluid Dyn., 54 (7), 927 (2019). DOI: $10.1134 / \mathrm{S} 001546281907005 \mathrm{X}$

[6] X. Hu, T. Cubaud. Phys. Rev. Lett., 121, 044502 (2018). DOI: 10.1103/PhysRevLett.121.044502

[7] F. Lin, A.N. Quraishy, T. Tong, R. Li, G. Yang, M. Mohebinia, Yi Qiu, T. Visha, J. Zhao, W. Zhang, H. Zhong, H. Zhang, Ch. Zhou, X. Tong, P. Yu, J. Hu, S. Dong, D. Liu, Zh. Wang, J.R. Schaibley, J. Bao. arXiv:2103.13564 [physics.flu-dyn]

[8] K. Gupta, K.M. Kolwankar, B. Gore, J.A. Dharmadhikariand, A.K. Dharmadhikari. Phys. Fluids, 32, 121701 (2020). DOI: $10.1063 / 5.0025469$

[9] В.А. Александров. Химическая физика и мезоскопия, 22 (1), 49 (2020). DOI: 10.15350/17270529.2020.1.6

[10] F. Denner, G. Pare, S. Zaleski. Eur. Phys. J., Special Topics, 226, 1229 (2017). DOI: 10.1140/epjst/e2016-60199-2

[11] Л.Д. Ландау, Е.М. Лифшиц. Гидродинамика (Наука, М., 1988) 